\title{
Tierra de Miranda. Revista do Centro de Estudos António Maria Mourinho (Miranda do Douro), 1, 2006, 104 p., ISSN : 1646-4982.
}

Voici la première livraison de la superbe revue consacrée à la « Tierra de Miranda », la seule région du Portugal où est parlée une langue autre que le portugais, à savoir le mirandais, langue asturo-léonaise. Le nom du centre d'études qui publie la revue est celui d'un célèbre curé du village de Dues Eigreijas (Duas Igrejas, en portugais officiel) qui redynamisa un groupe de danse de pauliteiros à partir des années 1940 et fut un infatigable chercheur ès culture et histoire mirandaises. La revue est dirigée par António Bárbolo Alves, auteur de la première thèse sur la langue mirandaise et lui-même écrivain en cette langue, et Maria Olinda Rodrigues Santana, professeure à l'université du Trás-os-Montes, avec l'appui de la municipalité de Miranda. Les articles inclus dans ce numéro sont en mirandais (un petit effort! tout lecteur de portugais y arrivera avec un peu d'habitude !), en portugais et en français. L'orientation de cette première livraison est très linguistique ou littéraire, ce que ne laisse pas forcément deviner le titre, qui est ouvert aux analyses sociales, économiques et politiques. On attendra donc les prochains volumes pour ces aspects. En tout cas, bienvenue à cet outil supplémentaire d'étude, défense et promotion de l'une des langues menacées d'Europe. [Contact : Centro de estudos António Maria Mourinhos, Biblioteca Municipal, Rua do Convento, 5210-021 Miranda do Douro, Portugal ; site : <http://ceamm.no.sapo.pt>, courriel : <centro. amm@gmail.com>].

Octobre 2007, Michel Gahen

\section{Plural Pluriel \\ Revue des cultures de langue portugaise}

Le premier numéro de la revue Plural Pluriel, printemps-été 2008, a été mis en

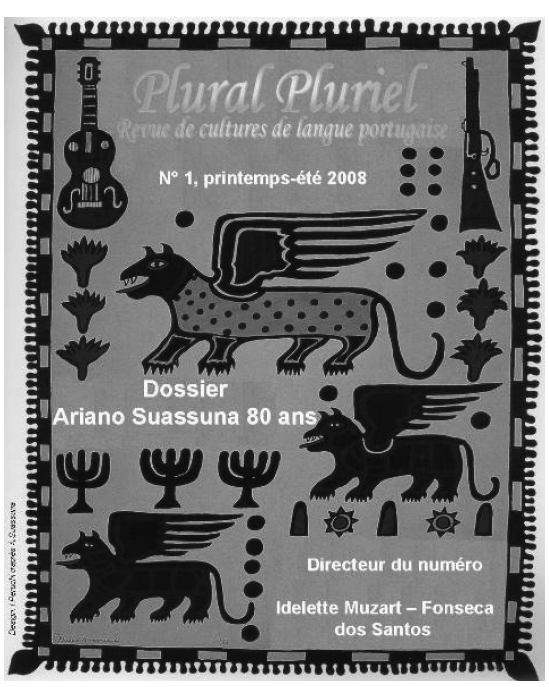
ligne en septembre 2008, à l'adresse : <http://www.pluralpluriel.org/>. La revue des cultures de langue portugaise est une revue bilingue, créée en 2008 par le Centre de Recherches Interdisciplinaires sur le monde Lusophone, CRILUS, membre de l'Equipe d'Accueil 369 «Études romanes » de l'Université Paris Ouest Nanterre - La Défense, anciennement Paris X - Nanterre. Elle bénéficie de l'appui de la Chaire Lindley Cintra de l'Institut Camões, créée à l'Université Paris Ouest Nanterre - La Défense en 2002 et du programme ARCUS Brésil-Chili, 2006-2008. La revue Plural Pluriel n'existe qu'en ligne, aucune version sur papier ou CD n'est prévue. Le premier numéro d'une revue, même électronique et 
virtuelle, a besoin d'un «parrain » de qualité : le choix d'un dossier consacré à «Ariano Suassuna : 80 ans », au-delà de l'admiration et de l'amitié, a donc semblé naturel parce que significatif d'ouverture à toutes les cultures portées par la langue portugaise. On peut s'enregistrer pour un meilleur suivi des nouveautés; donner son opinion et faire connaître cette nouvelle revue autour de soi! 